\title{
Dynamics Associated with the State of Cohabitation with Examples from a Few Countries of the Developing World. A Literature Review
}

\author{
Prof. S. M Kang'ethe \\ University of Fort Hare, Department of Social Work and Social Development \\ Private bag X1314, ALICE. 5700, South Africa \\ Email: skangethe@ufh.ac.za
}

Miss Itai Mafa

Masters of Social Work Student, University of Fort Hare P/B X1314, Alice, 5700

Email:200909691@ufh.ac.za

Doi:10.5901/mjss.2014.v5n14p601

\begin{abstract}
The pace at which cohabitation is increasingly becoming a norm in many African countries presents a challenge that African countries need to address. These countries need to stop blaming globalization, modernization, eurocentrism and western centric lifestyles as reasons wreaking havoc to their institutions of marriage and cultures. The aim of article is to explore, debate and form discourses on the factors underpinning the phenomenon of cohabitation with examples from developing countries. The article has used a review of literature methodology. The following factors underpin the phenomenon of cohabitation: weakening of moral and religious fibres; individuals need for financial security and desire for social affiliation and affection; and pressure from friends and relatives to get into a relation and sire children. The following present perfidious effects of cohabitation: susceptibility to conflict and violence, poverty and HIV/AIDS; and social stigma and societal condemnation. The article urges governments, faith based education and any marriage friendly bodies to intensify education on the perfidious effects of cohabitation. These bodies need to address all the underpinning factors such as poverty that forms a palatable environment to cohabitation.
\end{abstract}

Keywords; Illegal living arrangements, marriage, imperialism, colonialism, poverty, culture, moral decadence, HIVIAIDS

\section{Problem Statement}

With the family structures in various countries undergoing numerous alterations, cohabitation appears to be one of the common forms of acceptable forms of alternatives of marriage. However, it is a phenomenon marred with challenges that calls for an exploration with the hope of either discouraging it, or seeking to reduce its horrendous and pinching spin-offs. With increased spate of gender based violence among the cohabiting families, and the threat of the parties' susceptibility to HIVIAIDS, it is pertinent to prompt discussion, debate and exploration of the underpinnings of the phenomenon of cohabitation. This is to give hope of how such families can be helped out to formalize their union and possibly live in peace and harmony. The fact that this family union has no legal grounds leaves questions as to the future of children resulting from the union. This is mainly because of the lack of inheritance rights or a well defined plan of where the couple intend to do in the near future. Also, the uncertainty of whether the couples are married or single has been identified as a lead causal factor to all the flaws that surround cohabitation. This is what makes it a problematic arrangement.

\section{Methodology}

The paper has adopted a review of literature methodology and has immensely investigated literatures on various aspects of cohabitation, its niche in the contemporary global, regional and national marriage terrain, and its perfidious effects to the institution of marriage. The researchers have also used their intuitive observational skills to argue on the subject. 


\section{Introduction and Background}

In any continuum of life, change is usually an inevitable phenomenon, whether such a change is desirable or not. This may be because change results from efforts to achieve a desired outcome, which can sometimes be phenomenal and a result of factors one may not have control of (Rogers-Dillon, 2004). As such, change is usually a reflection and result of what is happening in the world, among countries and also in one's country. Therefore, aspects of globalization, westernization, eurocentrism, westernization and modernization have a major stake in determining and shaping the direction of change in the societies (Kange'the \& Mafa, 2014; Kang'ethe 2013). With the phenomenon of countries and regions that have erstwhile been very far from one another turning into a global village where all can communicate without major stumbling blocks, with increased advancement in information technology, this may have created a rich opportunity that has resulted in cultural and moral dilution (Kang'ethe 2014a). Although this development oriented factors have immense positive aspects and are desirable in many fronts and facets, their impacts are increasingly affecting the originality, uniqueness and morality of the African cultures (Afolayan, 2004; Kang'ethe 2009, 2013). However and besides the current influences of globalization that appear to spread its tentacles so fast in the developing part of the world, perhaps the western world that came to colonize continents such as Africans were selfish and did not want the nations they conquered to maintain their originality and uniqueness. This was selfish and an expression of their condescending attitudes and greed to towards especially the vulnerable nations. All they wanted was to spread their capitalistic and imperialistic ideologies so that the conquered nations could dogmatically follow their whims and wishes, notwithstanding the damage such processes espouses (Kang'ethe, 2009, 2013). Perhaps this background enlightens the readers on how African countries lost and are still losing their culture uniqueness, originality and morality, all in the name of westernization (Arowolo, 2010).

One of the institutions that has been immensely shaken and cut to size by the impacts of colonialism, modernization and globalization is marriage (Arowolo, 2010). Although African were both monogamous and polygamous, issues of sexual engagements outside marriage such as a man eloping with a girl he wanted to marry were highly discouraged and societies were very keen to solemnize them. People who wanted many partners were encouraged to consummate the marriage or have partners who were officially known by all, or concubines. Therefore the issue of cohabitation was not an African norm. Cohabitation is when a man and a woman live together without any marriage arrangements (Stephen, 2006). The union can end unceremoniously without any party laying blame on one another. It was ushered in by the colonialists who wanted to exploit women for a short spell of time, either to understand the communities before they would move to other stations for other assignments probably back home or other countries. On another note, the incarceration of men by colonialists through imposed taxes that forced them to migrate and work in farms owned by the colonialists or their collaborators sometimes made such men to seek psychological and physiological solace through clandestine union with some women. Although this was done for convenience and part time endeavour, it was in a way a form of cohabitation (Crowely, 2005). Once such a man went home, that could have spelt the doom of such an union. Cohabitation, therefore, came with green light of pre-marital sex, or sexual exploitation that took away the girl's state of virginity and pride (Yarber \& Sharp, 2010). These are phenomena that need to be seriously discussed especially today when the world especially the developing part of the world is under the weight and fire of HIVIAIDS (Ramphele, 2008; Barnett \& Whiteside, 2006). These researchers guess that after Africans accepted to follow the whims and cultures of the westerners, they appear to have taken a snail's pace in fighting to refuse and discard the culture. Today, cohabitation or what can be described loosely as come we stay living arrangements is now structured within the African ways of living. This implies that cohabitation, although an erstwhile abhorred phenomenon appears to increasingly find its ways in some countries' legal books (Tabata \& Boyes, 2013). For example in South Africa, many documents asking about one's marriage status, cohabitation norm features prominently. Who can now draw a line between a child from the African soil and the non- African? How do we try to fit our moral values into a western misfit?

\section{Understanding and Conceptualizing the Term Cohabitation}

It is rather a challenge to define a phenomenon such as cohabitation, with so much material written about it. Also, understanding this concept can be linked to one's moral values, beliefs as well as culture. This is mainly because the western culture interprets it differently from the Africans (Neckerman, 2004). However, the term is generally used to describe the relationship between unmarried couples who live together as husband and wife (Parry, 1981). This definition allude to the realisation that cohabitation is more of a testing ground for marriage, or a maybe a step on the way to marriage, more or less like dating and engagement. Stephen (2006) on the other hand adopts a broader definition to cohabitation. The writer above claims that the term denotes a situation in which two people live together in a family 
framework analogous to marriage, without actually having gone through the formalization of marriage. These two definitions differ profoundly in that the latter used the phrase 'two people' instead of 'man and woman', which was used in the former. The term cohabitation is used in the latter instance to include people of the same sex living together in a stable, exclusive relationship. Hence forth, the later definition recognizes homosexuals who are also cohabiting. Either way, the context of a cohabitational relationship entails consensual marital sex between the couple and a sense of responsibility towards each other (Stephen, 2006). Based on these scholars, it is observable that there are common elements of 'not being married' and 'living or staying together', or de facto marriages (Brown \& Booth, 1996). It should however be clear that the responsibilities are not formal, for example in accordance to the legal requirements of marriages. Such aspects may be instinctual or just informal and verbal. Many scholars have also disinterred that cohabiting is common now than a couple of years back. Crowely (2005) supports the above ideas as he echoes that the phenomenon of men and women who engaged in together casually, or what can be said to be cohabitation was immensely did not seek communal approval. Conversely, and in contemporary epoch, living together out of wedlock, once considered as "shacking-up" or "living-in-sin," has now lost its stigma as cohabitation has become worldly acceptable. This may be attributable to what Kange'the \& Mafa (2014) view as the effects of modernization, urbanization and westernization. The norms that were once regarded with high sacredness have now been stripped of their value with the emergence of one global culture. Whitman and Whitman (2003) are of the view that given the widely publicized data that half of the new marriages fail, couples see it logical to have a trial marriage to test the waters before actually walking on the isle. The bloodcurdling figures on divorce rates even in Africa are scaring away people from exchanging the sacrosanct marital vows. Neckerman (2004) calls them 'shortgun marriages' as they are short-lived. As much as this is not a validated excuse, it is however contributing to the reluctance of people to get married, opting for cohabitation instead. Addressing the issue of a time period that qualifies to be called cohabitation, this is a tricky and confusing aspect mainly because people have different interpretations of cohabiting. In most cases, the time period is irrelevant as long as the people cohabiting have made a conscious decision to live together.

\section{The Dynamics Associated with Cohabitation}

In an effort to comprehend cohabitation better, it is of great importance to firstly delve deeper into the factors that are associated with this phenomenon. Only in this way can the way forward be paved, with a full knowledge of the real facts on the table. The following aspects have been disinterred to form the underpinnings of the phenomenon of cohabitation.

\subsection{Weakening of moral and religious values}

Not so long ago especially in many African contexts and geographical locales, the phenomenon of cohabitation was a taboo. It was an abhorred and "no go zone' area phenomenon just as matrifocality (The World Bank, 2003) In fact, it was unheard of especially in Africa where culture and religious values condemned it. However, the $20^{\text {th }}$ century came with its own drastic changes, with immorality as one of the main manifesting characteristic of the millennium. Heitler, MyCrensky and Pauler (1997) are of the view that cohabitees are usually with a non-traditional and non-religious mindset. These researchers I believe this might have been true in the $19^{\text {th }}$ century. These days, even those who claim to be spreading the religious gospel and faith some are cohabiting as long as they moved in with the wives without any solemnization, either by the church or the societies. Perhaps the fact that some members of most faith based religious bodies are slowly asking for democracy in church leaves little ground for pinning down those who are cohabiting. This democracy is apparent in churches such as the African Independent Pentecostal Church of Africa (AIPCA) where polygamy is officially allowed (Kang'ethe \& Gaseitsiwe 2012). The uncontrollable increase of this pre-marital sex and in some cases nonmarital child bearing is evident of and donates the erosion of norms against behaviour that was traditionally condemned and associated by such harsh terms as promiscuity (Yarber \& Sharp, 2010). Yes, it is true that the African culture recognizes men with more than one wife. Yet still, as has been already explicated, a wife and a cohabitee are two different things altogether. This is mainly because there is no formalization of the union. As such, the living arrangement is not legally or socially recognized (with the exception of a few nations such as South Africa). Nevertheless, the fact that cohabitation is gaining social mileage and acceptance does not undermine the social ills it is dragging with it as normlessness and moral decadence are icing the African cake. This is a clear reflection of the slumber among parents, traditional and religious leaders who should be teaching the younger generation right from wrong (Killen \& Smetana, 2006; Lapsley \& Narvaez, 2004). 


\subsection{The need for financial security}

In a world of various packages of insecurity, be it social, psychological, financial or emotional, two individuals always reduces the horrendous and pinching effects of the above phenomena. Perhaps the perspective of group therapy and its strengthening impact in the lives of the group members needs to be appreciated (Trevithick, 2005). The need to partner is perhaps a stronger argument supported by the African adage that says that "two fingers can squash lice". Perhaps an English version of this is that two minds are better than one. With the cash nexus making the waves in today's life, people are strategising to ensure that the little money they have can go a long way. Urban poverty which is mainly as a result of lack of sustainable employability, resources can therefore be singled out as a push factor to cohabitation (GebreEgziabher, 2010). This is increasingly ushering a situation in which shelter, food, accommodation and water are daily problems (McDonald \& McMillen, 2010). As a result, people may decide to cohabit as a way of making sure that the ends meet. Hence forth, individuals may make a decision to cohabit, not because they love one another, no, but because of the feeling that life can be a bit blighter if the two can shares their pains and comfort. This, therefore, places the need to be together due to love a secondary consideration. They end up compromising their values, in an attempt to keep afloat. This is very true especially with migrants from Zimbabwe who come to South Africa in search of jobs. Zimbabwe as a nation unlike South Africa is highly against cohabitation. However, crossing the river Limpopo changes everything as the need to settle financial scores become a priority (Minujin \& Nandy, 2012). Such individuals have to do their mathematics carefully to ensure that they float, otherwise if not they can sink altogether. Considering the horrendous and pinching effects of the economy of their country, options such as cohabitation becoming an attractive norm for economic survival (McDonald \& McMillen, 2010). Coupled with cultural dilution and moral erosion, Zimbabweans find themselves bowing down to the culture of South Africans. Culture in this regard can be seen as the people's collective interpretation of circumstances, which is a guide to behaviour (Neckerman, 2004). Hence dilution of culture entails that the weaker element gives in to the dominant and most popular one.

\subsection{The need for affiliation and affection}

Abraham Maslow disinterred that human being in general have needs that are applicable to everyone (Wahba \& Bridwell, 1976). One of these needs is the desire to be loved and be accepted as a human being (Rogers, 1977). With marriage losing its viability (Yarber \& Sharp, 2010), many people are not hesitant to settle for the next best thing on the table, which is now cohabitation. This natural desire to belong and being cared for is another causal factor that is pushing up the statistics on cohabitation not just in Africa, but in the whole world. In some cases, some women have a dire desire to be a mother such that they are impatient to wait for a partner to offer a hand in marriage (Morrissette, 2007). Hence, they may cohabit with the hope of getting a child, whether the relationship takes off or breaks off. Such women may feel their desire and priority is a child, not a male partner. Neckerman (2004) believes that women gain a sense of identity and a sense of self worth through child bearing. This, then, becomes a strong reason to cohabit. This explains why some cohabiting couples never make it to the altar.

\subsection{Pressure from friends and family}

It is a desire of any traditional or religious parent to have their children get married one day. Children in an African context are socialized to be responsible and the notion of responsibility comes with being married and settling down (The World Bank, 2003). As such, achieving marriage becomes a deep routed desire or rather an achievement as it will be tattooed in one's mind and conscience. This desire may come a little earlier for others while others have to wait a little bit longer, if not forever. Plainly put, there are assorted factors that may work against this aspiration, some which may be beyond an individual's control. However, the longer the person waits for the right man or right woman to come, the more is the possibility of increased pressure that one settles down, or even get children. The case is even more intense where friends of one's age, or even sisters younger than oneself get married. Getting someone may actually become a mission where a person will channel all the energy to ensure that someone is available. As this pressure mounts, the person's tenacity to hold on to values and morals may be challenged, inevitably leading to one settling for some compromises (Yarber and Sharp, 2010). These researchers guess what is meant when people say "desperate times call for desperate measures". An individual will strip him/herself of all the morals that he/she would have held dear due to the state of desperation and the obligation to get married. As such, individuals especially women compromise by settling for cohabitation (Morrissette, 2007). This shows that many people lack the virtue of patience and as a result they give birth to effects of impatience because every decision taken is coupled with its own pros and cons. 


\section{The Perfidy of Cohabitation}

It is true that every coin has two sides. Whether one prefers the tail or head side is an individual choice. However, it is the thrust of this article to examine the perfidious underpinnings associated with cohabitation. These are outlined below.

\subsection{Conflict and violence}

Incontrovertibly, although cohabitating couples may be more susceptible to violence due to lack of commitment to one another, individuals being on a conflicting path and becoming violent towards one another is not uncommon phenomenon in human nature (Gender Link, 2012). The spate and magnitude of gender based violence especially in the southern African countries appears not to relent and societies and governments are worried how such spousal conflicts and violence can be surmounted (Kang'ethe, 2014b). As such, cohabiting couples are not immune to these predicaments. In fact, domestic violence in Africa is sometimes accepted as a gender role (The World Bank, 2003). However, the fact that cohabiting couples are literally sitting on the fence makes their position to engage in conflict more susceptible. This is because their commitment to the union may be weak and any small fire erupting in the relationship may not have any strong force to quench it, with both parties tending to find a soft landing and possibly tearing away with ease (Neckerman, 2004). As already pointed out by Rindfuss \& VandenHeuvel (1990), cohabitation poses great confusion even among the cohabitees as they are not certain if they are married or single. This confusion may lead to frustration and anxiety. The fact that the couple cannot decide whether they want to be married or to break-up depicts the highest level of indecisiveness and inability to commit themselves seriously to any issue that espouses serious commitment. To this end, Heitler (1997), a psychologist from Denver argues that agreeing to cohabit is putting oneself in a vulnerable position. The vulnerability maybe caused by the fact that one will be committing to an incomplete transaction where there are no guarantees or expectations whatsoever. The unavailability of clear gender roles in this relationship may also fuel up the tension as there is no clarity on responsibilities and house rules (Barlow et al. 2005). When the pressure mounts, cohabitees may ventilate their frustration on each other especially if one party is now fade-up with the arrangement. Kanchense (2008) is of the view that deprivation, abuse, oppression and social exclusion are fatal to women as they are the weaker vessels. Where children are concerned, this presents an unpalatable environment as children are likely to be exposed to even more vulnerability which is not of their making.

\subsection{Lack of vision}

The Holy Bible indicates that where there is no vision, people perish (MacArthur 1997). Incontrovertibly, where there is no vision, people are bound to fall into unforeseen pits as blind parties. Even though many people argue that marriage is losing its edge as it is now flawed with insecurity and highly unreliable (Yarber \& Sharp, 2010), these researchers strongly believe that it is the only familial arrangement that offers stability when iced with a vision. Espoused in vision, at least the couple will be clear of what they want and hence they can plan ahead. On the other hand, where there is no clear agreement, certificate or a proper plan, couples may be hesitant to invest in one other, be it financially or emotionally, due to the fear of the unknown. The lack of a written agreement entails that anyone can leave at any point in time, maybe even without warning. Evidently, the relationship will be a recipe of mediocrity and vacillation. No wonder many couples never make it to the point of tying the knot (Brown \& Booth, 1996). In the view of these researchers, cohabiting without getting married is a clear indication that there's something preventing the couple from making that commitment and merely living together does not miraculously take care of such issues. Testing the waters as it is sometimes called (Whitman \& Whitman, 2003), without knowing the depth of the river may bring about surprises with untold horrendous and pinching effects in life. The bottom line on this note is that the reluctance of the cohabiting couple to decide on the direction they want to take their relationship may actually be the causal factor of whatever challenges that they may face in the long run. Goals motivate people to wake up in the morning and have the energy to move on and dream in life. This is because they will be having something to look forward to, a hope to hold on to. This may not be situation with cohabiting couples whose relationship foundation is analogous to the biblical house which was built on the sand and not deeply immersed in strong background to withstand and weather the storms and turbulences of life (MacArthur , 1997)

\subsection{Social condemnation}

Although cohabitation is nothing worth talking about in South Africa, in Zimbabwe it is still highly condemned by anyone who hears about it, maybe because of their religious background (Neckerman, 2004). As a result, cohabiting couples are 
labelled, stereotyped against and sometimes seen as societal misfits. This is also true in traditionally routed nations such as Kenya and Uganda (Dlamini, 2006). Where condemnation, cursing and name tagging is always hanging over cohabiting couples, happiness tends to vanish as heaviness takes over. It is good to be famous, but being known by the community for something that is deemed unacceptable or immoral can pose both a daunting and a horrendous experience. This may be the case for cohabiting couples that live in bucolic areas where westernization and modernization is being resisted. Yarber \& Sharp (2010) are of the view that the state of cohabitation is also promoting matrifocal families as there is no formal agreement of the couple staying together. Religiously and socially, matrifocal families especially not caused by widowhood are also condemned as they are eroding the essence of a family unit that has always been male-led (Yarber \& Sharp, 2010). With all these factors waging contrary to cohabiting couples, more tension is pressed against them, ultimately leading to the dissolution of the arrangement. In a nutshell, as much as cohabitation is an individual choice, the societal customs, values and moral do play a crucial role in either promoting it or discouraging it. This is the power of culture whose impact cuts deeper than a sword (Neckerman, 2004).

\subsection{Increased vulnerability to HIV/AIDS}

With the widespread of the western culture and urbanization, pre-marital sex is now fashionable even among teenagers, whether adherents of faith based religious groups, or the cultural traditionalists (Yarber \& Sharp, 2010; The World Bank, 2003). In this regard, Kange'the \& Mafa (2014) argue that the media is also promoting such behaviour as the elders who were once advisors- have been replaced by Facebook and You Tube. Unfortunately, these young women and men have an imitating habit instead of having a listening ear. They no longer listen to the advice their elders have acquired through wisdom and experience. Instead, they are willing to take the risk and experiment on their own, in order to get first hand information. This is also the case with cohabitation. Despite the vast educational information on HIV and unwanted pregnancies, the World Bank (The World Bank, 2003) reported the low use of contraceptives, explaining the rapid spread of HIV in Africa. It is heart breaking to unearth that the Eastern and Southern Africa with only 5 per cent of the world's population, is home to half the world's population living with HIV. Today the region continues to be the epicentre of the HIVIAIDS epidemic, with 48 per cent of the world's new HIV infections among adults, 55 per cent among children, and 48 per cent of AIDS-related deaths (UNAIDS, 2013). Cohabiting couples subject themselves to high risks of infection because it is rare for a couple living together to use protection every time. They are bound to be caught off-guard or they get used to the idea. Yet still, they forget that they are not really committed to each other. As such multiple partners may happen. As far as promiscuity is concerned, The World Bank (2003) forwards that the predilection of men to hover among numerous sexual partners and their reluctance to be committed is causing family disintegration and subsequently the spread of HIVIAIDS. One can only wonder how many cohabitees an unstable person has in one life time, considering that they are practicing unsafe sex.

\section{Theoretical Frame}

\subsection{Moral Development Theory}

Cohabitation is not a crime that is punishable by law. The justification of whether it is right or wrong is not written in formal laws. Instead, cohabitation is better justified or condemned using moral lenses. The moral development theory seeks to further explore more on the reasoning behind cohabitation. This theory was propounded by Lawrence Kohlberg as he derived some of his ideas from the inspiring work of Jean Piaget. According to Kohlberg, humans develop systematically through social interaction (Barger, 2000). This entails that an individual has to go through the 6 steps as suggested by the profounder of the theory. These rather stages are thought to be invariant and definite as there is no room for jumping one stage to the next. According to Killen and Smetana (2006), moral judgement is fundamental to human judgement. In this regard, Lapsey and Narvaez (2004) argue that ignoring moral cognition poses a risk of destroying the moral nature. This clearly explains the prevalence of many inhuman aspects of life that have been adopted and normalised. Among these are sexual abuses, discriminations, prejudice and even cohabitation. It looks as if the conscience of humanity has been seared with a hot iron such that immorality is now celebrated. In explaining his stages, Kohlberg speak of the conventional stage where people seek to align their behaviour to societal demands and the formal laws of the nation (Barger, 2000). In other words, this marks the start of moral maturity where people are considerate of others, consider the impact and consequences of their actions that guarantee them becoming loyal and respectable citizens. These researchers believe that this is where people with good moral judgements consider marriage as a universally acceptable way of a family unit. Lapsley and Narvaez (2004) discovered that morality dilemmas are usually associated with relational 
(spouses, parents, children) and intrapsychic (welfare, rights, responsibilities) matters. This then calls for moral examplers to influence and mould behaviour. Kurtines and Gewirtz (2014) recognize the importance of parents, religious and traditional examplers to be able to steer the boat of morality in the right direction lest it wrecks. The fading away of the sacredness of marriage and other moral virtues such as honesty, faithfulness, compassion and forgiveness signals danger as far as African humanness is concerned. It seems as if most people are fixated on pre-conventional level where the stages are characterised by egoistic behaviour, self-centeredness and insensitivity (Barger, 2000). This lack of accountability can be seen in cohabiting couples. There is no commitment, everything is just temporary. No one is considering the long term future of the other, especially if children are concerned. The value of people is just on utility terms. Even though this theory is criticised for its obsession over processes and not content of reasoning (Kurtines \& Gewirtz, 2014), it gives a platform on which morality is derived. It is therefore time for each and every one of us to get out of our comfort zones and strive for the next stage on Kohlberg as each level marks better maturity and reasoning.

\section{The Way Foward}

Now that the causal factors to cohabitation and the drawbacks thereof have been analyzed, the next paragraphs cover the recommendations to curb the effects of cohabitation.

\subsection{Reinforcement of governmental policies that address the issue of cohabitation}

Any government is responsible for the welfare and well being of its citizens. Laws are formal norms that govern or determine the behaviour of the citizens. The financial, social and moral wellbeing of the citizens should be central to every government (Kanchense, 2008). The identity of each and every country is deeply rooted in the policies and laws that are enforced as benchmarks to determine behaviour. For example, a country which has agreed to same sex marriages obviously differs in terms of morality to the country that has forbidden homosexuality. Hence forth, this article suggests that the governments need to facilitate the mainstreaming of sex and marital education by having such education factored or be included in the school and institutional curriculum schedules that advocate for character education (Killen \& Smetana, 2006). Just talking about moral decadence brings no change until someone stands out and makes tangible steps towards total paradigm shift of behaviour. The South African courts have in a way helped these couples establish grounds to continue and therefore make cohabitation flourish. They have declared that cohabiting couples have an express or implied universal partnership. This entails that cohabitees are accorded the right to share properties that was acquired during the cohabiting period, following the amendment of the Domestic Bill Act (Hofmeyr, 2009). Traditional leaders, religious exemplers and cultural aspirators as part of the government also should take their stand in ensuring that morality is restored in Africa (Killen \& Smetana, 2006). If there is no partnership between all stakeholders concerned, injustice, loss of identity and a borrowed western culture will soon become the new identity of Africa.

\subsection{Reinforcement of moral and religious values}

An African person was originally known for African humanism, cultural identity, moral and sexual chastity, as well as good and appreciable morals (Kurtines and Gewirtz, 2014). This is an ingredient that used to demarcate Africans from the rest of the world. Regrettably, this is no more. These researchers are wondering and asking themselves where are the virtuous women and men of integrity for the continent to be proud of? If there is going to be hope at all in this generation or the ones to come, we need to go back to the drawing board. Retracing our footsteps to figure out where we took the wrong turn is critical, appreciable and considered a panacea (Lapsley \& Narvaez, 2004). If we have to, we need to wait on the crossroads until we have identified the old path that we were so proud of. This is a call of moral restoration, revival, renaissance, and religious revival and being proud of who we are. We have been exposed and obsessed to too much with western centric and eurocentric lifestyles that has deeply enslaved our thinking and ways of doing things. A paradigm shift that will emancipate us from this state of quagmire is necessary through moral, cultural and ideological reawakening and restoration. The media, external exposure and information technology have overwhelmed us so much such that we are not even sure where we have come from or going to (Kange'the \& Mafa, 2014). It is imperative for us to eat the flesh and throw away the bones. Let us be wise enough and courageous to take what is beneficial and constructive and letting go of destructive behaviour that is ticking away like a time bomb. Couture (2007) advocates that the church elders should take their positions as advisers and overseers in the task of grooming children, just like in the old good days. Parents also should direct every step that their children take, teaching them right from wrong. Kurtines 
and Gewirtz (2014) urge that it is the role of the family as the primary agent of socialization to mould a child against destructive behavior, reinforcing such admirable qualities as respect for self and others. That way, cohabitation with its other social ills will be eradicated. As it is right now, the decay is fast reaching the core where reversal would be almost impossible.

\subsection{Extensive education on social issues}

People indeed are perishing due to lack of knowledge. It is possible that due to unlimited information, individuals may find themselves embarking on a journey with no return. This is true in regard to cohabitation. Everyday many people sign up documents with terms and conditions they do not understand. Also, many people cohabit without the knowledge of the consequences or hurdles waiting ahead (Whitman and Whitman, 2003). It is therefore crucial for social agencies and those in social professionals to pick up their guns and position themselves ready to wage war against ignorance. Educational workshops, conferences and campaigns on the everyday issues like HIVIAIDS, gender-based violence and sex are imperative (The World Bank, 2003). Many may think that such topics are stale and boring but they are a rich source of information that may determine life or death for some people. As long as people are being infected with HIV and others still being abused then these educational campaigns are still needed. As long as there are unwanted pregnancies, then the gospel of the use of contraceptives and safe sex needs to be preached to all who acre to listen. If a big decision such as the choice to cohabit is to be made, it needs to be carried out by someone with all the information. According to Killen and Smetana (2006), knowledge is power. In fact, it is a bullet proof from certain predicaments in life. People, especially the younger generation should therefore never despise wisdom or neglect understanding for it is a source of life.

\section{Conclusion}

In conclusion, it is mandatory to highly highlight that this article does not seek to condemn cohabitation. Also, it is not meant to justify this kind of living arrangement. The thrust of this communiqué is however to provide in-depth information pertaining cohabitation. Arraying information in this way clearly reveals the social, moral and religious aspects that may need consideration before the finalization of a decision as people do not live like islands. This will aid couples in their decision-making as they will be aware of the situation they will be getting themselves into. A cost-benefit analysis is crucial as it will allow the weighing up of the available options in order to find a viable one that the couple will manage. Either way, life-changing decision such as cohabitation ought to be done cautiously and soberly to avoid regretting.

\section{References}

Afolayan, F. (2004). Culture and customs of South Africa. Greenwood Press Westernport, Connecticut. London

Arowolo, D. (2010). The Effects of Western Civilisation and Culture on Africa. Afro Asian Journal of Social Sciences. Volume 1, No. 1 Quarter IV. ISSN 2229 - 5313.

Barger, R.N. (2000). A summary of Lawrence Kohlberg's Stages of Moral Development. University of Notre Dame: Notre Dame, IN 46556.

Barlow A, Duncan S, James, G. \& Park, A. (2005) ."Cohabitation, Marriage and the Challenges for Social Work". Vol 1. England. Ashgate Publishers. Pg 125-132.

Barnett, T \& Whiteside, A. (2006). AIDS in the Twenty-First Century. Disease and Globalization. Hampshire: Palgrave Macmillan.

Brown, S.L \& Booth, A. (1996). "Cohabitation versus Marriage: A Comparison of Relationship Quality." Journal of Marriage and the Family. pp58: 668-678.

Couture, P. (2007). Child Poverty: Love Justice and Social Responsibility. Chalice Press: Danvers.

Crowely, D. (2005). The exploration of adolescent sex education programs taught in public schools. Sacramento State: California State University.

Dlamini, N. (2006). Measurement and Characteristics of Single Mother in South Africa: An Analysis Using 2002 General Household Survey. Unpublished Thesis, University of Kwazulu-Natal, South Africa. Pages 1-154.

Gebre-Egziabher, T. (2010). Livelihood and Urban Poverty Reduction in Ethiopia: Perspective from small and big towns. OSSREA Press: Addis Ababa.

Gender-Links. (2012).The Gender based Violence indicators Study Botswana.http://www.genderlinks.org.za/article/the gender-basedviolence-indicstudy-botswana-2012-03-28

Heitler S, MyCrensky, S \& Pauler, S. (1997). The Power of Two: Secret of a strong and Loving Marriage. New York: New Harbinger Publication.

Hofmeyr, C.D. (2009). Cohabitation and universal Partnership: Comfort Bedfellows. http:wwwcliffedekkerhofmeyr.com/en/news/press- 
releases/2009/cohabitation. html.

Kanchense, J. (2008). Zimbabwe's Child Brides: Using participatory Action to unleash Human Potential. Victoria: Trafford.

Kang'ethe, S.M. (2009). Traditional healers as caregivers to HIVIAID patients. Sahara journal. Vol. 6 (2). September, 2009. Pp.83-91

Kang'ethe, S.M. (2013). The panacea and perfidy of cultural rites of circumcision in African countries: Examples from Kenya, Botswana and South Africa. EASSRR Journal. Vol. xxix, no 1, pp. 107-123.

Kang'ethe, S.M \& Gaseitsiwe, B (2012). Religious Education for Form Three. Botsalano Publishers. Gaborone, Botswana.

Kang'ethe, S.M. (2014a). Panacea and perfidy of Globalization as an engine of social development in developing countries. In the press of Journal of Human Ecology , India.

Kang'ethe, S.M. (2014b). "The Woman and the Girl Child Phenomenon and Gender- Based- Violence (GBV) in Botswana" in Sven Hessle (ed). Human Rights and Social Equality: Challenge for Social Work. Vol 1. Stockholm, Ashgate Publishers. P125- 132

Kange'the, S. M \& Mafa, I. (2014). Dynamics associated with matrifocality in Zimbabwe. A Literature Review. Accepted for publication by the journal of Social Sciences and Anthropology, India.

Killen, M \& Smetana, J. (2006). Handbook of Moral Development. Lawrence Erlbaum Associations, Inc: New Jersey.

Kurtines, W.M \& Gewirtz, J.L. (2014). Handbook of Moral Behaviour and Development. Vol 1 Theory. Psychology Press: New York.

Lapsley, D.K \& Narvaez, D. (2004). Moral development, Self \& Identity. Lawrence Erlbaum Associates, Inc. New Jersey.

MacArthur, J (1997). The Holy Bible.

McDonald, J.F \& McMillen, D.P. (2010). Urban Economics and Real Estate: Theory and Policy. John Wiley \& Sons: Hoboken.

Minujin, A \& Nandy, S. (2012). Global Child Poverty and Well Being: Measurement, Concepts Policy and Action. The Policy Press: Bristol.

Morrissette, M. (2008). Choosing Single Motherhood: The Thinking Women's Guide. Wadsworth: Belmont.

Neckerman, K.M. (2004). Social Inequality. Russell Sage Foundation: New York.

Parry, M.L. (1981).Cohabitation: Social work and Law. Sweet and Maxwell: London

Ramphele, M. (2008). Laying Ghosts to Rest. Dilemmas of the Transformation in South Africa. Cape Town: Tafelberg. Report. Participatory education, evaluation and research, 2008.

Rindfuss, R.R \& VandenHeuvel, A. (1990). Cohabitation: A precursor to Marriage or an Alternative to being Single? Population Council. Pp 703-726.

Rogers-Dillon, R.H. (2004). Welfare Experiments: Politics and Policy Evaluation. CA: Stanford University Press.

Rogers, C. (1977). Carl Rogers on personal power: Inner strength and its revolutionary impact. New York: Delacorte Press.

Stephen, L. (2006). A comparison of marriage and cohabiting relationships. Journal of family issues. Volume 16-1:53-76.

Tabata, S \& Boyes, B. (2013). Universal Partnership. STBB Thought of the week: Common Law Spouse? Not in South Africa.

Trevithick, P. ( 2005). Social work skills. A practice handbook. Second edition. Open University Press.McGraw-Hill Education, McGrawHill House, England.

The World Bank, (2003). Caribbean Youth Development: Issues and Policy Directions. Washington DC.

UNAIDS. (2013). Global Report. UNAIDS Report on the global AIDS epidemic 2013. Geneva. Switzerland.

Wahba, M.A \& Bridwell, L.G. (1976). Maslow Reconsidered. A review of research on the need hierarchy theory. Organizational Behaviour and Human Performance. Vol. 15, Issue 2, April 1976. Pg 212-240.

Whitman, W \& Whitman, S. (2003). Shacking Up -The Smart Girls Guide to living in sin without getting burned. Broad Way Books: New York.

Yarber, A.D \& Sharp, P.M. (2010). Focus on the Single Parents families: Past Present and Future. Greenwood: California. 